\title{
The Impact of Anxiety, Depression, and Stress on Emotional Stability among the University Students from the view of educational aspects
}

\section{El impacto de la ansiedad, la depresión y el estrés en la estabilidad emocional entre los estudiantes universitarios desde el punto de vista educativo}

\author{
Shahla ALI AHMED \\ Near East University, Turquía \\ ORCID: https://orcid.org/0000-0002-5337-9160 \\ Yağmur ÇERKEZ \\ Near East University, Turquía \\ ORCID: https://orcid.org/0000-0002-3379-1035
}

Recibido 12-12-19 Revisado 13-02-20 Aprobado 20-04-20 En línea 29-04-20

Correspondencia

Email: yagmur.cerkez@neu.edu.tr
Citar como:

ALI AHMED, S., ÇERKEZ, Y. (2020). The Impact of Anxiety, Depression, and Stress on Emotional Stability among the University Students. Propósitos y Representaciones, 8(3). doi: http://dx.doi.org/10.20511/pyr2020.v8n3.520 


\section{Summary}

In the contemporary society, depression, anxiety, and stress are much more common than it was in history. The recent studies have outlined that the young adults are experiencing depression and anxiety disorders that is affecting their emotional and mental well-being. Aim of this co-relational survey model study is to investigate the impact of anxiety, depression and stress on emotional stability in terms of gender, age, year of study, department and place they stay. The study adapted pre-designed questionnaires to collect data. The sample of the study consists of approximately 260 undergraduate university students from University of Sulaymaniyah in Northern Iraq. The researcher adapted two scales first Henry and Crawford scale that call DASS for measuring the level of anxiety, depression, and stress and second one to measure Emotional stability using a self-reported scale. The collected data was analyzed using SPSS version 22 to find result for this thesis. The results of the study outlined that there is a negative but significant correlation among depression, anxiety, and stress with emotional stability. Also there is no significant relationship between emotional stability in terms of gender and age, other findings of the study show that DASS has no significant relationship with age, and year of study and place of stay in generally, but there a significant difference between DASS in terms of gender and department.

Keywords: Stress; Anxiety; Depression; Emotional Stability; DASS

\section{Resumen}

En la sociedad contemporánea, la depresión, la ansiedad y el estrés son mucho más comunes que en la historia. Los estudios recientes han señalado que los adultos jóvenes están experimentando trastornos de depresión y ansiedad que están afectando su bienestar emocional y mental. El objetivo de este estudio modelo de encuesta correlacional es investigar el impacto de la ansiedad, la depresión y el estrés en la estabilidad emocional en términos de género, edad, año de estudio, departamento y lugar donde permanecen. El estudio adaptó cuestionarios prediseñados para recopilar datos. La muestra del estudio consta de aproximadamente 260 estudiantes universitarios de pregrado de la Universidad de Sulaymaniyah en el norte de Irak. El investigador adaptó dos escalas primero, la escala de Henry y Crawford, que llaman DASS para medir el nivel de ansiedad, depresión y estrés, y la segunda para medir la estabilidad emocional usando una escala autoinformada. Los datos recopilados se analizaron utilizando SPSS versión 22 para encontrar el resultado de esta tesis. Los resultados del estudio esbozaron que existe una correlación negativa pero significativa entre la depresión, la ansiedad y el estrés con la estabilidad emocional. Además, no existe una relación significativa entre la estabilidad emocional en términos de género y edad, otros hallazgos del estudio muestran que DASS no tiene una relación significativa con la edad y el año de estudio y el lugar de estadía en general, pero hay una diferencia significativa entre DASS en términos de género y departamento.

Palabras clave: Estrés; Ansiedad; Depresión; Estabilidad emocional; DASS

\section{Introduction}

Many people experience anxiety depression and stress at some stage during their life. They are also direct symptoms caused by the chemical changes in the brain. Depression, anxiety and stress can cause so many diseases that can be long-term or short-term sever or curable. Depression and anxiety are although related to the brain but these mental disorders can impact the emotions significantly. People with anxiety, depression, and stress would not be open to the society and would keep their pain to themselves. They would suffer from severe mood swings, may be 
difficult to handle, could over react to situations, have an introverted personality and would be socially isolated (Horwitz, 2010). Furthermore, anxiety is a feeling of fear, nervousness or unease. It may bring on a particular response within the body such as a racing heartbeat, sweating, or feelings of breathlessness. Whereas, depression is more than just a low mood - it is a serious condition that has an impact on both physical and mental health. Depression can be low, moderate or severe. Depression involves intense feelings of sadness or low mood for long periods of time (weeks, months or years). This study will describe the impact of anxiety, depression and stress on emotional stability to overcome this issue for an improved emotional stability. To improve emotional stability, it is important to overcome stress, anxiety, and depression for a healthy wellbeing (Pestonjee, 1992).

Similarly, stress is the body's way of responding to any kind of demand or threat. When sense danger whether it is real or imagined, the body's defenses kick into high gear in a rapid, automatic process known as the fight-or-flight reaction or the "stress response. The stress response is the body's way of protecting. Stress isn't always bad. In small doses, it can help perform under pressure and motivate. But when there is constantly emergency mode, mind and body pay the price. Lovibond and Lovibond, (1995) identified health problems caused or exacerbated by stress as: (Depression and anxiety, Pain of any kind, Sleep problems, Autoimmune diseases, Digestive problems ,Skin conditions, such as eczema, Heart disease, Weight problems ,Reproductive issues and Thinking and memory problems).

Pastorelli, Barbaranelli, Cermak, Rozsa, and Caprara (1997) identified that emotional stability refers to a person's ability to remain stable and balanced. At the other end of the scale, a person who is high in neuroticism has a tendency to easily experience negative emotions. A study was conducted by Wani and Sankar (2016) to outline the emotional stability among the students of the university in India. The results of the study revealed that girls and boys presented the same emotional stability mean scores. It highlighted that frequency of occurrence of the emotional stability doesn't depend upon the gender of the students. The results of the study also depicted that stability of science and the general groups were similar in the mean scores. The study by Horwitz (2010) revealed that anxiety, stress, and depression are emotional conditions. This disorder is very common and it can be experienced by any individual at different stages of life. Horwitz (2011) found that Major depressive disorder is a serious mental disorder, which has serious effects on the life of any individual. The study conducted by Griffiths, Crisp, Berney, and Reid (2011) outlines the significance of seeking help from family and friends in depression and anxiety. The results revealed that support from friends and family helped in understanding the emotions. It made them emotionally stable and advises from them help in overcoming stress and depression.

Kaiser and Ozer (1997) researched on the relationship between anxiety and emotional stability. They outlined that anxiety and emotional stability are closely associated. with that the study by Reich, Noyes, Coryell, and O'Gorman (1986) examined the effect of state anxiety on the behavior of individuals, the study discovered that state anxiety may occur in human beings but it causes personality issues in affected people. Pestonjee (1992) suggests that stress occurs when the demands on any individual exceed his available resources. He believes that stress is usually harmful to the health and the performance of any individual. Mikolajczak, Menil, and Luminet (2007) also researched on the emotional stability and stress relationship. They outlined that stress and emotional stability are also closely related to each other than anxiety and emotional stability.

In the contemporary society, depression, anxiety, and stress are much more common than it was in history. The recent studies have outlined that the young adults are experiencing depression and anxiety disorders that is affecting their emotional and mental well-being. This is also one of the commonly observed social issues in the society that I came from. There are so many of my friends and people in my social network that are experiencing these issues. Therefore, 
I want to describe the impact of anxiety, depression and stress on emotional stability. In this way, I can help people to overcome this issue and maintain a healthy life. Thus, the aim of this study is to investigate the impact of anxiety, depression and stress on emotional stability in terms of gender, age, year of study, department and place they stay

\section{Methods}

The study is a quantitative research. The study is co-relational survey model as its aim was to describe the relationship between depression, anxiety, and stress with emotional stability. The study adapted pre-designed questionnaires to collect data. Also the sample of the study consists of approximately 260 undergraduate university students from University of Sulaymaniyah in Northern Iraq. The questionnaire was divided among 300 students but the researcher received 260 questionnaire forms filled by participants. The participants were purposively selected from different departments through purposive sampling technique. The researcher included males and females, participants of different age groups, different year of study, different departments in order to answer the research questioners and to achieve the aim of the study. And the collected data was analyzed using Statistical Program for Social Science (SPSS) version 22.

There are four variables in the research, three independent variables, stress, anxiety, and depression and one dependent variable that is emotional stability. The researcher collected the data for these four variables using pre-designed questionnaires. To get result the researcher adapted Henry and Crawford (2005) scale for measuring the level of anxiety, depression, and stress among the participants. The scale is called as DASS which is a set of three self-report scales. DASS had 21 items. Emotional stability was measured using a self-reported scale with twenty items adapted from Pastorelli, Barbaranelli, Cermak, Rozsa, and Caprara (1997).

The reliability of the tools used in the study to collect the data were test through SPSS using Cronbach's Alpha Coefficient to determine the instruments used for the data collection are reliable enough to draw discussions and conclusions. Cronbach's Alpha value for DASS is (.776) and alpha value for Emotional stability scale is (.683) Similarly, the researcher did not compromise on the validity of the instrument used for data collection. The questionnaire was first translated into Kurdish language and before the participants filled the questionnaire, it was translated back to English language and then both questionnaires were compared to correct any minor error. The researcher also presented the questionnaire to the three professionals to ensure validity.

\section{Finding and result}

Is there a significant relationship between anxiety, depression, and stress with the emotional stability of the university students?

The findings of the study suggest that there is a negative but significant correlation between depression, anxiety and stress with emotional stability. $\mathrm{P}<0.05, \mathrm{r}=-0,35, \mathrm{P}<0.05, \mathrm{r}=-$ 0,151 and $\mathrm{P}<0.05, \mathrm{r}=-0,257$ as see in Table 1 . 
Table 1.

Correlation análisis

\begin{tabular}{lccccc}
\hline & & \multicolumn{2}{c}{ Emo } & Depre & Anxiety \\
Stress & & & & & \\
\hline Emo & Pearson Correlation & 1 & $-.354^{* *}$ & $-.151^{*}$ & $-.257^{* *}$ \\
& Sig. (2-tailed) & .000 & .015 & .000 & \\
& $\mathrm{~N}$ & 259 & 259 & 259 & 259 \\
\hline Depre & Pearson Correlation & $-.354^{* *}$ & 1 & $.440^{* *}$ & $.553^{* *}$ \\
& Sig. (2-tailed) & .000 & & .000 & .000 \\
& $\mathrm{~N}$ & 259 & 260 & 260 & 260 \\
\hline Anxiety & Pearson Correlation & $-.151^{* *}$ & $.440^{* *}$ & 1 & $.408^{* *}$ \\
& Sig. (2-tailed) & .015 & .000 & & .000 \\
& $\mathrm{~N}$ & 259 & 260 & 260 & 260 \\
\hline Stress & Pearson Correlation & $-.257^{* *}$ & $.553^{* *}$ & $408^{* *}$ & 1 \\
& Sig. (2-tailed) & .000 & .000 & .000 & \\
& $\mathrm{~N}$ & 259 & 260 & 260 & 260 \\
\hline
\end{tabular}

**. Correlation is significant at the 0.01 level (2-tailed).

*. Correlation is significant at the 0.05 level (2-tailed). students?

Is there a significant difference between the emotional stability of male and female

The findings suggest that there is no significant relationship between the emotional stability in terms of gender as $\mathrm{P}>0.05, \mathrm{t}=0.616$. as mentioned in Table 2. with an effect size of 0.07 that we can say small size effect, according to Cohen's $d$ that 0.2-0.5 include small size effect.

Table 2.

Independent Samples T-Test for emotional stability and gender

\begin{tabular}{lccccccc}
\hline & & $\mathbf{N}$ & Mean & Std. Deviation & $\mathbf{t}$ & df & Sig.(2-tailed) \\
\hline EMO & Female & 143 & 3.2615 & .50287 & .616 & 257 & 0.538 \\
& Male & 116 & 3.2233 & .48947 & & & \\
\hline
\end{tabular}

Is there a significant difference between the emotional stability in terms of age?

The findings of the study suggest that there is no significant effect between emotional stability in terms of age as mentioned in Tables 3, The $\mathrm{P}>0.05$ and $\mathrm{F}(2,256)=0.408$.

Table 3.

ANOVA for age and emotional stability

\begin{tabular}{llllllll}
\hline & & Sum of Squares & df & Mean Square & F & P \\
\hline Emo & Between Groups & .202 & 2 & .101 & .408 & .666 \\
& Within Groups & 63.353 & 256 & .247 & & \\
\hline & Total & 63.554 & 258 & & & \\
\hline
\end{tabular}

Is there a significant difference between the depression, anxiety and stress in terms of year of study? 
The findings of the study suggest that there is no significant effect between depression, anxiety, stress and year of study, as Depression $\mathrm{P}>0.05$ and $\mathrm{F}(4,255)=1.187$, as Anxiety $\mathrm{P}>0.05$ and $\mathrm{F}(4,255)=.554$ and as Stress $\mathrm{P}>0.05$ and $\mathrm{F}(4,255)=1.734$.

Is there a significant difference between the depression, anxiety and stress in terms of department?

The findings of the study suggest that there is significant correlation among anxiety, stress and department of students as anxiety has $p<0,05$ and $F(6,253)=4,527$, and stress has $\mathrm{p}<0,05$ and $\mathrm{F}(6,253)=2,610$ also there is not significant correlation between depression and department of students as depression has $\mathrm{p}>0,05$ and $\mathrm{F}(6,253)=1.863$, as mentioned in Table 4, However, in the Post Hoc Test, it was found that the difference was in anxiety levels between medical faculty and education, arts, and humanities department, also difference was in anxiety levels between education faculty and medical, science department, with that there is difference was in anxiety levels between art and humanities faculty and medical and physical \& basic education also last one there is difference was in anxiety levels between science faculty and education and art and humanities as $\mathrm{P}=0.001$. With that LSD test also there is difference was in stress levels according to faculty.

Table 4.

ANOVA for depression, anxiety, and stress with department

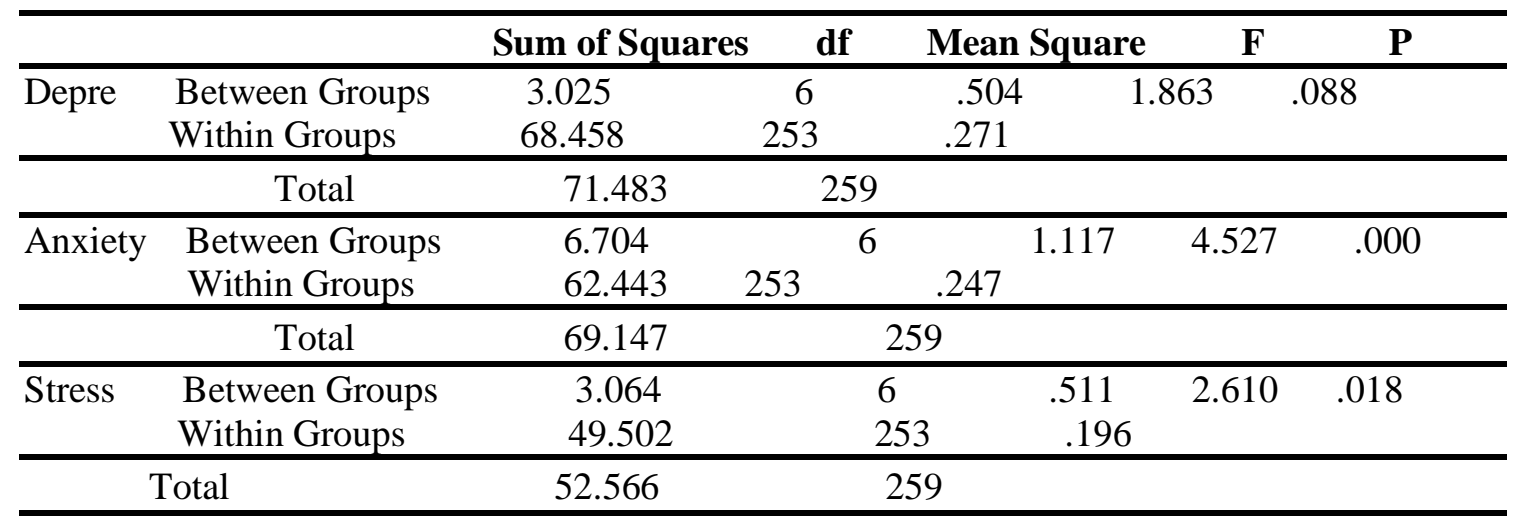

Is there a significant difference between the depression, anxiety and stress in terms of place they stay?

The findings of the study suggest that there is no significant relation between depression, anxiety, stress and place of stay. as Depression P $>0.05$ and F $(2,257)=.615$, as Anxiety $\mathrm{P}>0.05$ and $F(2,257)=.052$ and as Stress $P>0.05$ and $F(2,257)=1.343$.

Is there a significant difference in DASS total scores in terms of gender, age, year of study, department and place of stay?

The findings of the study show that DASS has no significant relationship with age, and year of study and place of stay in general.

The findings of the study suggest that there is significant difference between the DASS in terms of gender. as $\mathrm{P}<0.05, \mathrm{t}=2$. 569. as mentioned in table 5, with an effect size of 0.3 that we can say small size effect, according to Cohen's d that 0.2-0.5 include small size effect.a 
Table 5.

Independent Samples Test for DASS and gender

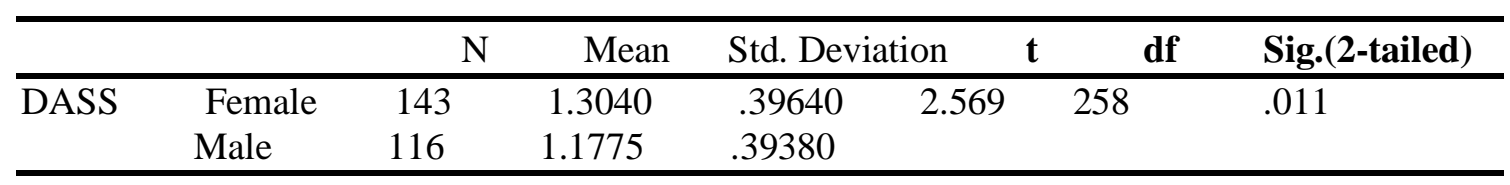

The findings of the study suggest that there is no significant relationship between DASS in terms of age as observed as mentioned in Table 15 and 16 . The $P>0.05$ and $F(2,257)=0.122$.

The findings of the study suggest that there is no significant relationship between DASS in terms of year of study. The P>0.05 and $F(4,255)=1.297$.

The findings of the study suggest that there is no significant relationship between DASS in terms of place of stay .The $\mathrm{P}>0.05$ and $\mathrm{F}(2,257)=.381$.

The findings of the study show that DASS has significant relationship with gender, department in general.

The findings of the study suggest that there is significant correlation among DASS and department of students as $\mathrm{p}<0,05$ and $\mathrm{F}(2,253)=3,845$. however in the Post Hoc Test, it was found that the difference was in DASS levels between medical faculty and education, also there is difference was in DASS levels between Education faculty and medical and science faculty with that there is difference was in DASS levels between Engineering faculty and science faculty and result show that the difference was in DASS levels between Science faculty and education and engineering faculty as $\mathrm{P}=0.001$. as mentioned in Table6.

Table 6.

ANOVA for DASS and Department

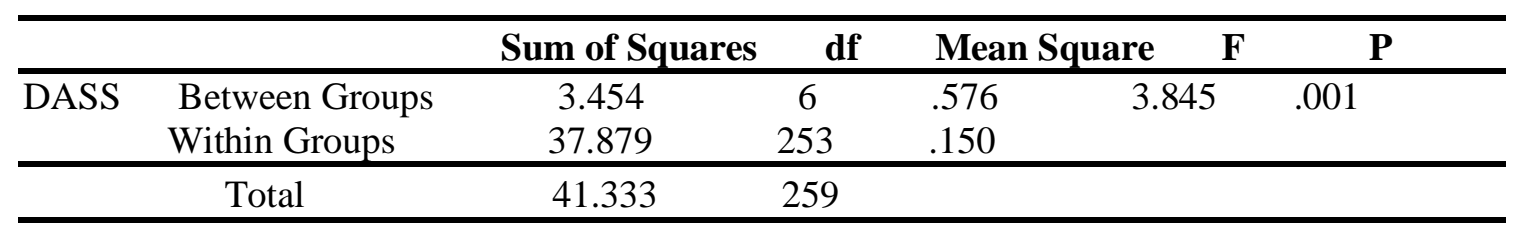

\section{Discussions of the findings}

The findings of the study demonstrated similar results with the existing studies in the relevant field. Kaiser and Ozer (1997) researched on the relationship between anxiety and emotion stability. They outlined that anxiety and emotional stability are closely associated. The experience of pro-active and reactive stress is related to goals, which was examined as a function of the trait of emotional stability. The findings revealed that emotional stability is related to both anticipatory and reactive stress in the health domain. The study discovered that emotional stability is not related to the kind of stress in the organization and material wealth domains. In this regard, the reasons for these differences and suggestions for using trait and goal units are discussed.

Mikolajczak, Menil, and Luminet (2007) also researched on the emotional stability and stress relationship. They outlined that stress and emotional stability are also closely related to each other than anxiety and emotional stability.

The study by Horwitz (2010) revealed that anxiety, stress, and depression are emotional conditions. This disorder is very common and it can be experienced by any individual at different 
stages of life. This disorder occurs due to the different reasons which, varies person to person. Depression, stress, and anxiety are not considered healthy for any individual as it can limit mental development. It also casts an effect on the emotional stability of any person.

A study was conducted by Wani and Sankar (2016) to outline the emotional stability among the students of the university in India. They used the quantitative research method to evaluate the emotional stability of university students. The results of the study also depicted that stability of science and the general groups were similar in the mean scores. On detailed analysis, it was found that boys are generally more emotionally stable than the girls. The study indicated that students of the general discipline were found to be more emotionally stable than the students of the science group.

To study the impact of school demands on the daily time use and subjective states of young people in India, Verma, Sharma, and Larson (2002) conducted the study. It was seen that lower average emotional states and more internalizing problems were observed in students those who spent more time doing their homework. The study showed that those Indian students who spent more time in leisure experienced more satisfactory states but they faced a higher level of academic anxiety and lower educational success.

The study conducted by Schreiner and Malcolm (2008) investigated the changes caused in the emotional states of anxiety, depression, and stress. The study outlined the advantages of mindfulness meditation which can help in developing emotional stability. It was observed that stress and anxiety level was decreased after the program. The training helped all the people to lower their stress and become emotionally stable. The results suggested that mindfulness training is very effective to reduce the symptoms of depression and anxiety.

Salleh (2008) conducted a study to highlight the relationship between stress, illness and life events, It was also discussed that not all stress types are negative. The study outlined the psychiatric illness caused by stress. Hence, many existing studies support the argument presented in the study and outlined in the findings of this research. Emotional stability is affected by stress, depression, and anxiety among young learners.

\section{Conclusion}

Stress, depression and anxiety are becoming very common. It depends upon many factors. The study was performed to evaluate the impact of anxiety, stress and depression on emotional stability. As the result Emotional stability is negatively but significant correlated with Depression, Anxiety and stress .also There is no significant difference between the emotional stability of men and women. We came to know that there is not any particular difference in emotional stability in case of gender.

However, the results indicated that there is no significant relationship between emotional stability and age. And the fundamental point of the present investigation was to distinguish the impact of a year of concentrate on the dimension of worry among the understudies in a depression; stress and anxiety do not depend upon the year of study. There is a significant connection among anxiety and stress with department Anxiety and stress levels may vary according to the fields and departments. 


\section{References}

Henry, J. D., \& Crawford, J. R. (2005). The short-form version of the Depression Anxiety Stress Scales (DASS-21): Construct validity and normative data in a large non-clinical sample. British journal of clinical psychology, 44(2), 227-239.

Horwitz, A. V. (2011). Creating an age of depression: the social construction and consequences of the major depression diagnosis. Society and Mental Health, 1(1), 41-54.

Horwitz,A.V. (2010). How age of anxiety became an age of depression. The Milbank Quarterly, $88(1), 112-138$.

Kaiser, R. T., \& Ozer, D. J. (1997). Emotional stability and goal-related stress. Personality and Individual Differences. 22(3), 371-379.

Lovibond, P., \& Lovibond, S. (1995). The structure of negative emotional states: Comparison of the Depression Anxiety Stress Scales (DASS) with the Beck Depression and Anxiety Inventories. Behavior research and therapy, 33(3), 335-343.

Mikolajczak, M., Menil, C., \& Luminet, O. (2007). Explaining the protective effect of trait emotional intelligence regarding occupational stress: Exploration of emotional labor processes. Journal of Research in Personality, 41(5), 1107-1117.

Pastorelli, C., Barbaranelli, C., Cermak, I., Rozsa, S., \& Caprara, G. V. (1997). Measuring emotional instability, prosocial behavior and aggression in pre-adolescents: a crossnational study. Personality and Individual Differences, 23(4), 691-703.

Pestonjee, D. M. (1992). Stress and coping: The Indian experience. Retrieved from Stress and coping: The Indian experience.

Reich, J., Noyes, R., Coryell, W., \& O'Gorman, T. W. (1986). The effect of state anxiety on personality measurement. Am J Psychiatry, 143(6), 760-763.

Salleh, M. R. (2008). Life Event, Stress, and Illness. Malays J Med Sci., 15(4), 9-18.

Schreiner, I., \& Malcolm, J. P. (2008). The Benefits of Mindfulness Meditation: Changes in the Emotional States of Depression, Anxiety, and Stress. Behavior Change, 25(3), 156-168.

Verma, S., Sharma, D., \& Larson, R. W. (2002). School stress in India: Effects on time and daily emotions. International Journal of Behavioral Development, 26(2), 500-508.

Wani, M. A., Sankar, R., Angel, J., \& Dhivya, P. (2016, September ). Emotional Stability among Annamalai University Students. The International Journal of Indian Psychology, 3(4), 119-123. 